\title{
The Centricity Score: A Novel Measurement to Aid in Conservative Breast Cancer Surgery
}

\author{
Ryan Sugrue, Katherine McGowan, Cillian McNamara, Michael Sugrue* \\ Department of Breast Surgery and Radiology Letterkenny and Donegal Clinical Research Academy, National \\ University of Ireland, Galway, Ireland \\ Email: ${ }^{*}$ michael.sugrue@hse.ie
}

Received 26 July 2014; revised 23 August 2014; accepted 20 September 2014

Copyright @ 2014 by authors and Scientific Research Publishing Inc.

This work is licensed under the Creative Commons Attribution International License (CC BY).

http://creativecommons.org/licenses/by/4.0/

c) (i) Open Access

\begin{abstract}
Introduction: This study describes an intra-operative scoring system to advise the surgeon of the centricity of the tumour in the excised specimen. Methods: Spatial estimations were prospectively made in 10 consecutive patients undergoing wide local excision (WLE) using Bioptics intra-operative digital specimen imaging. The centricity score was defined as $100-($ ICD/SD $\times 100)$, where ICD is the inter-centre distance between the specimen's centre and the tumour's centre. Results: 10 patients with invasive breast cancer (T1b to T4a), mean age 56 years (range 44 - 71) were studied. The mean tumour and specimen diameter was $24 \mathrm{~mm} \pm 10$ (range 12 - 48) and $101 \mathrm{~mm} \pm 22$ (range 64 - 140). The mean centricity score was $86 \pm 9$ (range 65 - 95). Conclusion: This study successfully describes an intraoperative radiological spatial scoring system for patients undergoing WLE. Tumours were well centered in specimens with an overall score of $86 / 100$. The centricity score could be used to guide excision and potentially set benchmarks for conservative breast surgery.
\end{abstract}

\section{Keywords}

Breast Cancer, Wide Local Excision, Positive Margins, Re-Excision Rates, Specimen Radiography

\section{Introduction}

The majority of patients diagnosed with breast cancer now opt for breast conserving surgery [1]. While wide local excision (WLE) may reduce morbidity and promote excellent cosmesis [2], there is a risk of re-operation for positive margins. This is associated with additional physical and psychological consequences for the patient and financial costs to the health service.

From a surgical perspective, ideally the tumour should be as close to the centre of the excised specimen and

"Corresponding author.

How to cite this paper: Sugrue, R., McGowan, K., McNamara, C. and Sugrue, M. (2014) The Centricity Score: A Novel Measurement to Aid in Conservative Breast Cancer Surgery. Advances in Breast Cancer Research, 3, 118-123. 
out of this concept the centricity score developed. Fundamentally the more central the tumour is in the excision specimen the higher the score. The higher the score the better, indicating the tumour should be more eqi-distant from the margin and theoretically reduce risk of margin involvement. Margin status is the primary determinant of local recurrence after breast conserving therapy (BCT) [3] and the rate of re-excision [4].

From a patient perspective, it is important to achieve an excellent cosmetic effect. This is essentially obtained by avoiding excessive excision. The larger the volume excised the worse the cosmetic outcome [5], This balance between a good oncological outcome and an appropriate cosmetic effect reflects the "success" of a WLE and also forms the basis for The Centricity Score.

Rates of re-excision vary internationally with an average of 25\%, ranging from $10 \%-54 \%$ [1] [6] and therefore remain a major challenge in health care delivery. Although re-excision rates cannot themselves be used as a quality measure in breast cancer care delivery, multiple operations are undesirable [1] and wide variations that exist indicate a potential gap in quality of care [7]. This potential shortfall in patient care is not helped by scarcity of aids to assist a surgeon in performing complete tumour excision at the index operation.

This study assesses the feasibility of measuring the centricity of breast cancer in the surgical specimen during wide local excision.

\section{Materials and Methods}

A prospective study was undertaken in 2012 in Letterkenny Hospital, Donegal, Ireland-a regional designated provider of breast cancer care-to measure the centricity score in a sample of 10 consecutive patients undergoing WLE. Letterkenny Hospital is a satellite centre with its parent cancer centre at University College Hospital Galway (UCHG) under the Irish National Cancer Control Program designation.

The centricity score was defined by the formulae; $100-(\mathrm{ICD} / \mathrm{SD} \times 100)$, where ICD is the inter-centre distance between the breast specimen's centre and the tumour's centre. The specimen diameter (SD) is measured along the long axis of the specimen. Both values are calculated in millimeters using the intra-operative specimen $\mathrm{X}$-ray of the excised breast specimen (Figure 1). Specimens were orientated with a standard specimen marking system, with three clips superior, two clips anterior and one clip medial. Margins were considered positive if tumour was at the inked surface or close, if within $2 \mathrm{~mm}$ [7]. A score of 100 would be considered a perfect score indicating the tumour was the exact centre of the excised breast specimen ("bull's-eye"). As the specimen diameter increases there will be a reduction in the centricity score. Tumour and specimen measurements were obtained both radiologically and pathologically and included mass, width, length and depth. The tumour distance to nearest margin was also calculated. Perpendicular margin assessment was used where the tumour was close to the margin; otherwise macroscopic measurement was used [8].

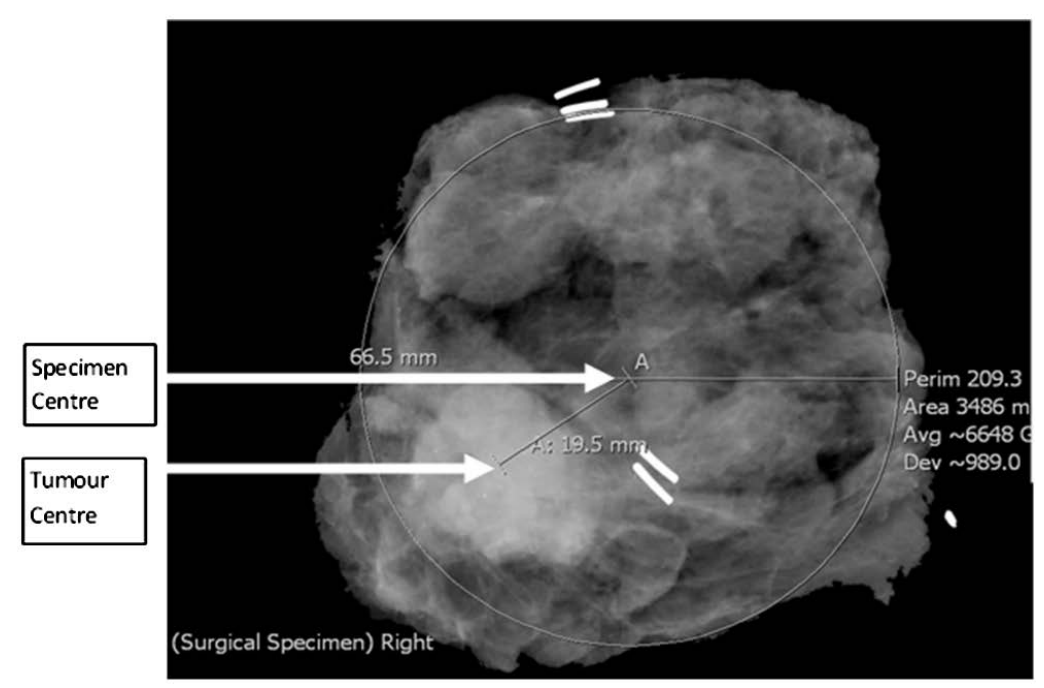

Figure 1. Specimen X-ray with marking clips demonstrating Centricity Score Cal- culation. The ICD is $19.5 \mathrm{~mm}$ between the Specimen and Tumour Centres (SC and TC) $[\mathrm{CS}=100-(19.5 \mathrm{~mm} / 66.5 \mathrm{~mm} \times 100)]=70.7$ 
Patient demographics and histology were recorded. Patients with primary DCIS or mammographically occult cancers were not included. Data was expressed as mean, standard deviation and range. Specimen radiographs were performed using Bioptics ${ }^{\circledR}$ intra-operative digital specimen imaging. One standard non-compressed AP view was obtained following a standard specimen orientation by a single consultant surgeon and operating theatre staff, guided by written protocols. The specimens were carefully placed by the attending surgeon on the positioning plate with a protocol for orientation in the AP plane. Specimen X-rays were taken in the OR and were available in 3 minutes. Lateral views were done but were not used in the calculation of the centricity score. Images were then analyzed and recorded with Agfa IMPAX 6.4 radiological imaging. The study was approved by the hospital ethics committee.

\section{Results}

10 consecutive patients, mean age was 56 years (range 44 - 71), with a mean BMI of 25 (range 22 - 26) with invasive ductal breast cancer were studied. All patients were symptomatic and 9/10 had palpable lesions, 1/10 had a non-palpable cancer and underwent wire guided localization prior to excision. All patients had invasive cancer, ductal in 9 and lobular in 1 . The mean tumour diameter was $24 \mathrm{~mm}$ (range 12 to $48 \mathrm{~mm}$ ) and grade 1 in 1/10, grade 2 in 5/10 and grade 3 in 4/10. 8/10 were ER/PR positive and 2 were HER2 positive. There was associated ductal carcinoma in situ (DCIS) in 4/10 and one had an extensive intra-duct component. Lymphovascular invasion (LVI) was present in 5. There was associated ductal carcinoma in situ (DCIS) in 4/10. The margins were clear, and none were close, either radiologically on the specimen X-ray or on histology in all patients. No patient underwent re-excision. The mean specimen weight was $129 \mathrm{~g} \pm 8.5 \mathrm{~g}$ (range 29 - $240 \mathrm{~g}$ ). The mean centricity score was $86 \pm 9$ (65.3 - 94.5). All other parameters are shown in Table 1 . The nearest radiological margin was $15 \mathrm{~mm}$ and the furthest $24 \mathrm{~mm}$.

\section{Discussion}

This study describes a novel method of recording the spatial intra-operative location of a breast cancer's relative position within the excised specimen in patients undergoing conservative breast surgery. This is one of the first studies to describe an objective radiological assessment of tumour location in wide local excision specimens.

This method is founded on two important principles. Firstly, understanding the importance of achieving a "clear margin" histologically free of any residual tumour whilst avoiding excessive resection. The strongest predictor of local recurrence remains that of surgical margin status [3] [9] [10]. Despite this, there is currently no consensus regarding the definition of a negative margin [4] [11]. Secondly, there is a surprisingly large variation in positive margins and re-excision rates [1] [6]. Re-excision rates themselves are not a true quality indicator as there is a large international interpretational variation on what constitutes a positive margin and need for re-op-

\begin{tabular}{|c|c|c|c|c|c|}
\hline $\begin{array}{l}\text { Patient } \\
\mathrm{N}=10\end{array}$ & $\begin{array}{l}\text { Specimen Max Diameter } \\
\text { (mm) }\end{array}$ & $\begin{array}{l}\text { Tumour Max } \\
\text { Diameter (mm) }\end{array}$ & $\begin{array}{l}\text { Intercentric Distance } \\
(\mathbf{m m})\end{array}$ & $\begin{array}{l}\text { Margin Distance } \\
(\mathbf{m m})\end{array}$ & Centricity Score \\
\hline Patient 1 & 64 & 22 & 6.3 & 15.2 & 90.2 \\
\hline Patient 2 & 92.4 & 16.9 & 12.5 & 24.2 & 86.5 \\
\hline Patient 3 & 110.1 & 19.3 & 6.1 & 24.5 & 94.5 \\
\hline Patient 4 & 100.4 & 14.5 & 34.8 & 15.3 & 65.3 \\
\hline Patient 5 & 121.6 & 31.5 & 22.6 & 21.8 & 81.4 \\
\hline Patient 6 & 111.2 & 24.9 & 13.2 & 23.1 & 88.1 \\
\hline Patient 7 & 78 & 12.1 & 5.4 & 15.9 & 93.1 \\
\hline Patient 8 & 140.1 & 48.3 & 13.7 & 16.1 & 90.2 \\
\hline Patient 9 & 103.7 & 24.5 & 8.2 & 17.4 & 92.1 \\
\hline Patient 10 & 90.4 & 23.9 & 16 & 18.2 & 82.3 \\
\hline Mean \pm SD & $101 \pm 22$ & $24 \pm 10$ & $14 \pm 9$ & $19 \pm 4$ & $86 \pm 9$ \\
\hline
\end{tabular}


eration. Some surgeons will aim for a macroscopic margin of $1 \mathrm{~cm}$, whilst others aim for a $2 \mathrm{~cm}$ margin [11]. More so, some surgeons value and perform intra-operative specimen radiography; others use intra-operative ultrasound (US). This variation in surgical philosophy suggests that the technique of breast wide local excision, although a relatively simple surgical procedure, may not achieve the planning and analysis it deserves both from a pre-operative work-up and intra-operative approach. Essentially, there is a need to raise surgical awareness for the importance of centrally locating the tumour in the excised specimen. There are conflicting views in the surgical literature regarding whether consultant surgeons obtain superior results than trainees, either supervised or unsupervised [12].

While outcome determination in itself is not an exact science even with the use of objective analysis tools, quality of life is important after breast cancer surgery and may reflect the operative approach [13]. To suggest that there can be a standard approach to an individual patient's breast cancer would be naive. Confounders include patient breast size, breast density, need for localization, type of tumour histology, presence of DCIS and the position within the breast.

Since its introduction over 50 years ago breast surgical specimen radiography has been a controversial area. Some authors favour the technique, while others argue that it does not correlate with a positive/negative histological margin [14]-[16], or in DCIS the mammographic appearance of calcification often does not reflect the extent of the cancer on the final histology. To counter these limitations and enhance the value of specimen radiography, a number of modifications have been suggested: notably, two-dimensional views, compression, use of grids and fluid immersion [17]. The specimens in this study were uncompressed to avoid distortion [17] [18] and the centricity score used refers to one plane (antero-posterior) only. As far back as 1990, Aitkin [19] has advocated two-dimensional specimen radiology to enhance the spatial perception of the tumour in the specimen. The centricity score used in this only looks at one plane. The lateral view on specimen X-ray in general does not provide as much useful information as the AP view. It is generally accepted that the radial rather than the anterior and posterior margins are keys to outcome. Many intra-operative aids have been suggested including pre-operative radio-isotope guided seeds, Quantum-Dot Molecular Probe, radiofrequency spectroscopy with the Margin Probe [20]-[25].

There are definite specific limitations to the centricity score. Patients undergoing neo-adjuvant therapy, where tumour regression occurs may result in inability to radiologically localize the tumour. Such patients were not included in this pilot study. More so, peripherally placed tumours will not and should not be in the centre of the excised specimen and hence the centricity score described here is not useful for this subgroup of patients.

The centricity score will also be unhelpful in radiological occult tumors. Patients with lobular cancer often fall into this category, as will patients with DCIS. Patients with DCIS even when visible on mammogram, will have more extensive disease than that predicted on the mammogram.

While this surgery was undertaken by a single consultant in this study, it has been suggested that residents' performance in completely excising tumour may not be inferior to consultant [12]. It is unclear from the literature whether high volume surgeons have lower re-excision rates, with some studies in favour [26] and some against [6].

Whilst margin indexes have been reported in pathological margin assessment, existing radiology systems do not provide robust intra-operative measurement [27] [28]. The margin indexes previously reported are histologically based and look at edge rather than centre of tumour, the margin index has failed external validation as a predictive tool for margin involvement [28]. The uniqueness of the centricity score lies in the fact that it can be easily calculated intra-operatively. This ease of access and instant feedback creates a new market in breast surgery. The centricity score provides the very important ability to predict a potential positive margin [29] [30] and could potentially focus the mind of the surgeon. More so, by incorporating the specimen diameter into the centricity score formula, it's an attempt to regulate excessive excisions as a large specimen will result in a reduced need for re-excision but have adverse cosmetic and outcome measures for the patient [31]. Recent consensus guidelines on WLE margins produced by the American Society of Clinical Oncology, American Society for Radiation Oncology, and Society of Surgical Oncology indicating that no ink on tumour is now considered an adequate margin will also help reduce re-excision [32].

This study only describes the measurements and spatial analysis and in itself does not provide a validation of the score. Internal and external validation would be required before wider use could be advocated. It can, in its current format, provide a semi-objective analysis of a surgeon's ability to centrally locate an excised tumour within a specimen. We now routinely undertake the centricity score, calculated by the surgical team using ma- 
nual mapping on the digital radiology system. This analysis can provide a standardized means of comparison between surgeons. This may aid in resident training and in the future offer a potential tool to reduce some of the excess variability in conservative breast surgery.

\section{Conflict of Interest Statement}

The Authors declare that there is no conflict of interests.

\section{Funding Source}

None.

\section{Ethical Approval}

The study was approved by the hospital ethics committee.

\section{References}

[1] Jeevan, R., Cromwell, D.A., Trivella, M., et al. (2012) Reoperation Rates after Breast Conserving Surgery for Breast Cancer among Women in England: Retrospective Study of Hospital Episode Statistics. BMJ, 345, e4505.

http://dx.doi.org/10.1136/bmj.e4505

[2] Fisher, B., Anderson, S., Bryant, J., et al. (2012) Twenty-Year Follow-Up of a Randomized Trial Comparing Total Mastectomy, Lumpectomy, and Lumpectomy Plus Irradiation for the Treatment of Invasive Breast Cancer. NEJM, 347, 1233-1241. http://dx.doi.org/10.1056/NEJMoa022152

[3] Park, C.C., Mitsumori, M., Nixon, A., et al. (2000) Outcome at 8 Years after Breast-Conserving Surgery and Radiation Therapy for Invasive Breast Cancer: Influence of Margin Status and Systemic Therapy on Local Recurrence. Journal of Clinical Oncology, 18, 1668-1675.

[4] Morrow, M., Harris, J.R. and Schnitt, S.J. (2012) Surgical Margins in Lumpectomy for Breast Cancer-Bigger Is Not Better. NEJM, 367, 79-82. http://dx.doi.org/10.1056/NEJMsb1202521

[5] Olivotto, I.A., Rose, M.A., Osteen, R.T., et al. (1989) Late Cosmetic Outcome after Conservative Surgery and Radiotherapy: Analysis of Causes of Cosmetic Failure. International Journal of Radiation Oncology*Biology*Physics, 17, 747-753. http://dx.doi.org/10.1016/0360-3016(89)90061-8

[6] McCahill, L.E., Single, R.M., Aiello Bowles, E.J., et al. (2012) Variability in Re-Excision Following Breast Conservation Surgery. JAMA, 307, 467-475. http://dx.doi.org/10.1001/jama.2012.43

[7] Morrow, M., Katz, S.J. (2012) The Challenge of Developing Quality Measures for Breast Cancer Surgery. JAMA, 307, 509-510. http://dx.doi.org/10.1001/jama.2012.74

[8] Moo, T.A., Choi, L., Culpepper, C., Olcese, C., Heerdt, A., Sclafani, L., et al. (2014) Impact of Margin Assessment Method on Positive Margin Rate and Total Volume Excised. Annals of Surgical Oncology, 21, 86-92. http://dx.doi.org/10.1245/s10434-013-3257-2

[9] Bedwinek, J.M., Perez, C.A., Kramer, S., et al. (1980) Irradiation as the Primary Management of Stage I and II Adenocarcinoma of the Breast. Cancer Clinical Trials, 3, 11-18.

[10] Singletary, S.E. (2002) Surgical Margins in Patients with Early-Stage Breast Cancer Treated with Breast Conservation Therapy. The American Journal of Surgery, 184, 383-393. http://dx.doi.org/10.1016/S0002-9610(02)01012-7

[11] Blair, S.L., Thompson, K., Rococco, J., Malcarne, V., Beitsch, P.D. and Ollila, D.W. (2009) Attaining Negative Margins in Breast-Conservation Operations: Is There a Consensus among Breast Surgeons? Journal of the American College of Surgeons, 209, 608-613. http://dx.doi.org/10.1016/j.jamcollsurg.2009.07.026

[12] Aguilar, B., Sheikh, F., Pockaj, B., Wasif, N. and Gray, R. (2011) The Effect of Junior Residents on Surgical Quality: A Study of Surgical Outcomes in Breast Surgery. The American Journal of Surgery, 202, 654-657. http://dx.doi.org/10.1016/j.amjsurg.2011.05.018

[13] Sugrue, R., MacGregor, G., Sugrue, M., Curran, S. and Murphy, L. (2013) An Evaluation of Patient Reported Outcomes Following Breast Reconstruction Utilizing Breast Q. The Breast, 22, 158-161. http://dx.doi.org/10.1016/j.breast.2012.12.001

[14] Britton, P.D., Sonoda, A.K., Yamamoto, B., Koo, B., Soh, E. and Goud, A. (2011) Breast Surgical Specimen Radiographs: How Reliable Are They? European Journal of Radiology, 79, 245-249. http://dx.doi.org/10.1016/j.ejrad.2010.02.012 
[15] Graham, R.A., Homer, M.J., Katz, J., Rothschild, J., Safaii, H. and Supran, S. (2012) The Pancake Phenomenon Contributes to the Inaccuracy of Margin Assessment in patients with Breast Cancer. The American Journal of Surgery, 184, 89-93. http://dx.doi.org/10.1016/S0002-9610(02)00902-9

[16] Bimston, D.N., Bebb, G.G. and Wagman, L.D. (2000) Is Specimen Mammography Beneficial? Archives of Surgery, 135, 1083-1086. http://dx.doi.org/10.1001/archsurg.135.9.1083

[17] Chilcote, W.A., Davis, G.A., Suchy, P. and Paushter, D.M. (1988) Breast Specimen Radiography: Evaluation of a Compression Device. Radiology, 168, 425-427. http://dx.doi.org/10.1148/radiology.168.2.3393660

[18] Clingan, R., Griffin, M., Phillips, J., Coberly, W. and Jennings, W. (2003) Potential Margin Distortion in Breast Tissue by Specimen Mammography. Archives of Surgery, 138, 1371-1374. http://dx.doi.org/10.1001/archsurg.138.12.1371

[19] Aitkin, R.J., Going, J.J. and Chetty, U. (1990) Assessment of Surgical Excision during Breast Conservation Surgery by Intraoperative Two-Dimensional Specimen Radiology. British Journal of Surgery, 77, 322-323. http://dx.doi.org/10.1007/s00268-012-1577-1

[20] Bernardi, S., Bertozzi, S., Londero, A.P., Gentile, G., Giacomuzzi, F. and Carbone, A. (2012) Incidence and Risk Factors of the Intraoperative Localization Failure of Nonpalpable Breast Lesions by Radio-Guided Occult Lesion Localization: A Retrospective Analysis of 579 Cases. World Journal of Surgery, 36, 1915-1921. http://dx.doi.org/10.1007/s00268-012-1577-1

[21] Cox, E.C., Furman, B., Stowell, N., Ebert, M., Clark, J., Dupont, E., et al. (2003) Radioactive Seed Localization Breast Biopsy and Lumpectomy: Can Specimen Radiographs Be Eliminated? Annals of Surgical Oncology, 10, 1039-1047. http://dx.doi.org/10.1245/ASO.2003.03.050

[22] Allweis, T.M., Kaufman, Z., Lelcuk, S., Pappo, I., Karni, T., Schneebaum, S., et al. (2008) A Prospective, Randomized, Controlled, Multicenter Study of a Real-Time, Intraoperative Probe for Positive Margin Detection in Breast-Conserving Surgery. The American Journal of Surgery, 196, 483-489. http://dx.doi.org/10.1016/j.amjsurg.2008.06.024

[23] Feldman, S.M. (2013) Editorial-Surgical Margins in Breast Conservation. International Journal of Surgical Oncology, 2013, Article ID: 136387. http://dx.doi.org/10.1155/2013/136387

[24] Murphy, J.O., Moo, T.A., King, T.A., Van Zee, K.J., Villegas, K.A., Stempel, M., et al. (2013) Radioactive Seed Localization Compared to Wire Localization in Breast-Conserving Surgery: Initial 6-Month Experience. Annals of Surgical Oncology, 20, 4121-4127. http://dx.doi.org/10.1245/s10434-013-3166-4

[25] Ramos, M., Diaz, J.C., Ramos, T., Ruano, R., Aparicio, M., Sancho, M., et al. (2012) Ultrasound-Guided Excision Combined with Intraoperative Assessment of Gross Macscopic Margins Decreases the Rate of Reoperations for NonPalpable Invasive Breast Cancer. The Breast, 22, 520-524. http://dx.doi.org/10.1016/j.breast.2012.10.006

[26] Cancela, M., Comber, H. and Sharp, L. (2013) Hospital and Surgeon Caseload Are Associated with Risk of Re-Operation Following Breast-Conserving Surgery. Breast Cancer Research and Treatment, 140, 535-544. http://dx.doi.org/10.1007/s10549-013-2652-5

[27] Margenthaler, J.A., Gao, F. and Klimberg, V.S. (2010) Margin Index: A New Method for Prediction of Residual Disease after Breast-Conserving Surgery. Annals of Surgical Oncology, 17, 2696-2701. http://dx.doi.org/10.1111/j.1524-4741.2012.01249.x

[28] Bolger, J.C., Solon, J.G., Power, C. and Hill, A.D. (2012) Analysis of Margin Index as a Method for Predicting Residual Disease after Breast-Conserving Surgery in a European Cancer Center. Annals of Surgical Oncology, 19, $207-211$.

[29] Atalay, C. and Irkkan, C. (2012) Predictive Factors for Residual Disease in Re-Excision Specimens after Breast-Conserving Surgery. The Breast Journal, 18, 339-344. http://dx.doi.org/10.1111/j.1524-4741.2012.01249.x

[30] Waljee, J.F., Hu, E.S., Newman, L.A. and Alderman, A.K. (2008) Predictors of Re-Excision among Woman Undergoing Breast-Conserving Surgery for Cancer. Annals of Surgical Oncology, 15, 1297-1303. http://dx.doi.org/10.1245/s10434-007-9777-x

[31] Krekel, N.M., Haloua, M.H., Cardozo, A.M.L., de Wit, F.H., Bosch, A.M., de Widt-Levert, L.M., et al. (2013) Intraoperative Ultrasound Guidance for Palpable Breast Cancer Excision (COBALT Trial): A Multicentre, Randomised Controlled Trial. The Lancet Oncology, 14, 48-54. http://dx.doi.org/10.1016/S1470-2045(12)70527-2

[32] Moran, M.S., Schnitt, S.J., Giuliano, A.E., Harris, J.R., Khan, S.A., Horton, J., et al. (2014) Society of Surgical Oncology-American Society for Radiation Oncology Consensus Guideline on Margins for Breast-Conserving Surgery with Whole-Breast Irradiation in Stages I and II Invasive Breas: Cancer. Journal of Clinical Oncology, 32, 1507-1515. http://dx.doi.org/10.1200/JCO.2013.53.3935 
Scientific Research Publishing (SCIRP) is one of the largest Open Access journal publishers. It is currently publishing more than 200 open access, online, peer-reviewed journals covering a wide range of academic disciplines. SCIRP serves the worldwide academic communities and contributes to the progress and application of science with its publication.

Other selected journals from SCIRP are listed as below. Submit your manuscript to us via either submit@scirp.org or Online Submission Portal.
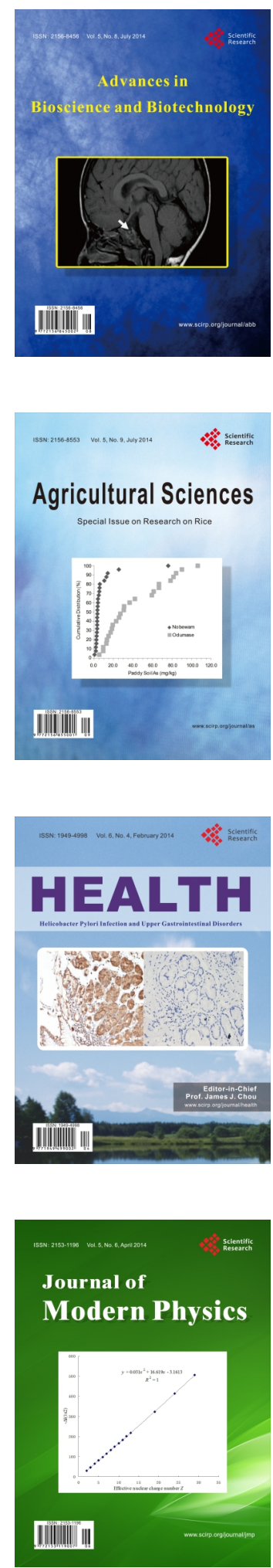
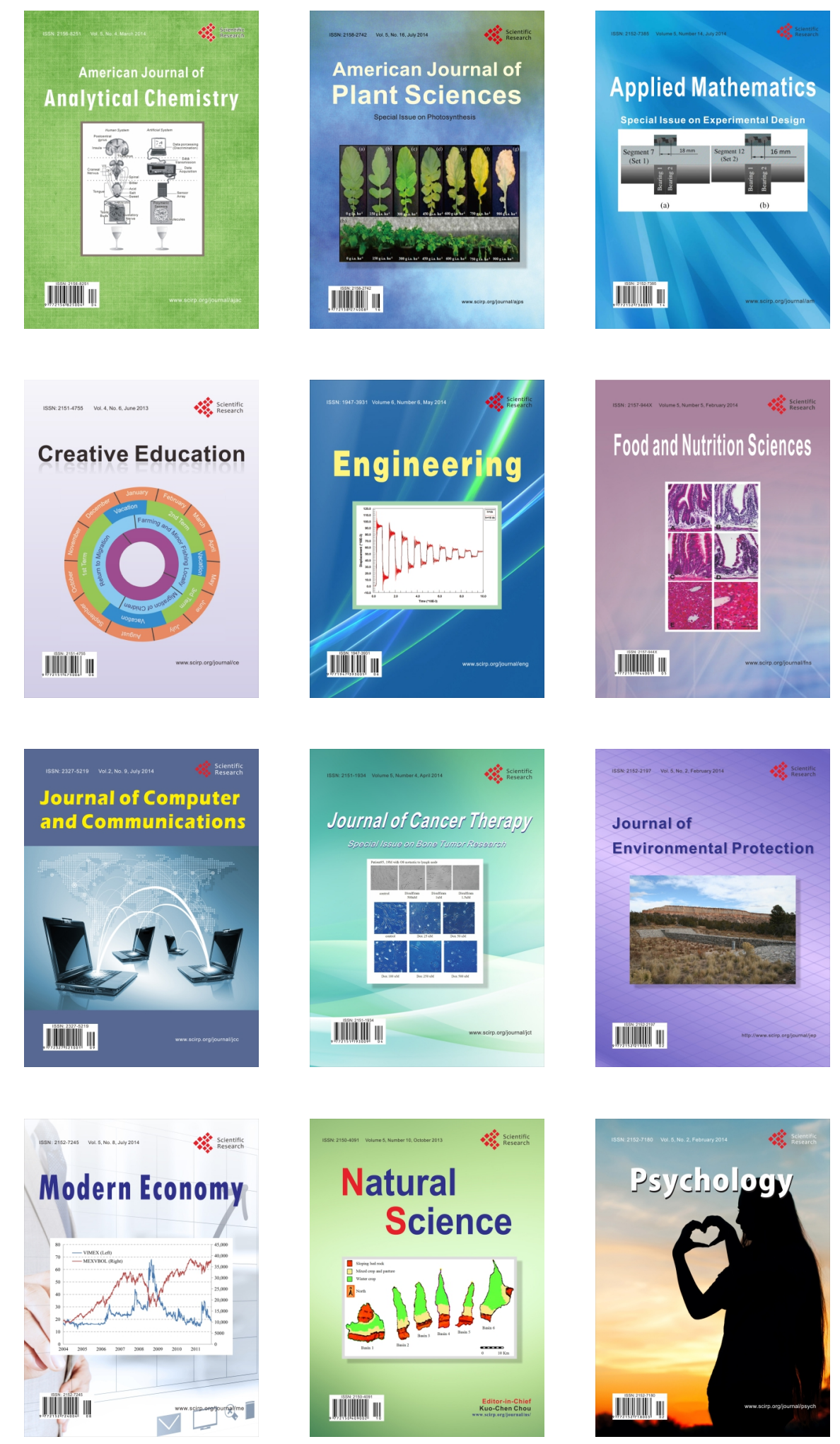